\title{
The Editor's Art: A Stylistic Study of the Daily Trust Editorial of September 3, 2015 on Military Debt
}

\author{
Murana. Muniru Oladayo \\ Department of European Languages- Federal University Birnin-Kebbi- Nigeria \\ muranamuniru1@gmai1.com
}

Abdul Wahab. Hafsat

Department of English- Government Secondary School- Dakace- Zaria- Nigeria

hafsymuran@gmail.com

\begin{abstract}
The task of persuasive writing is usually very demanding as the human target is a complex thinker. Editorials are presumably composed for the consumption of the elite with the aim of achieving a change in society. Consequently, issues of national relevance constitute the targets on which editorial opinions are written. The paper examines the September 3 edition of the Daily Trust newspaper of Nigeria to determine its stylistic devices for achieving impartiality in presenting the news it analyses, ensuring balanced analysis and providing convincing judgment. It finds that the editor employs flexible reporting style through his admixture of direct and indirect reportage strategies to ensure fairness; balances its argument through appropriate lexical choices; and displays critical resourcefulness through parallel and heavily beaded rhetorical questions, evaluative adjectives and unambiguous speech act verbs. The paper concludes that these devices constitute the editor's tools for enlightening the reader and motivating national development in relation to the topic of his composition.
\end{abstract}

Keywords: stylistics, editorial, Daily Trust Newspaper

\section{Introduction}

The modern society thrives on information which is central to awareness, literacy and education. A major sector that trades in collection, spread and analysis of information for the purpose of mass consumption is the newspaper company. The practice of news publishing preselects the target audience - the literate. The English medium newspapers particularly in English as Second Language situations are read by readers of varied levels of literacy. Perhaps the varieties of features in the newspaper such as politics, cartoon, sports news, photo news, obituary, health reports and editorial among others are to pave way for large readership accommodation.

The editorial is a genre of journalistic writing that arguably has a premeditated audience. Its readers, judging by its refined language of presentation, are competent readers. The editor's target is often to present and evaluate the news report in a way that leaves the readers with no other option than to be convinced. Achieving conviction involves planned persuasion whose basis resides in apt use of language. The editor's artistic engagement reflected in lexical and structural manipulations is the concern of this paper. It sets out to unfold how the editor maintains impartiality in the presentation of the primary report; how balanced analysis is achieved and the kind of strategies employed to convincingly articulate judgment. 


\section{The Newspaper Editorial}

An editorial is a genre of the newspaper report that is evaluative in its orientation and referential in its discussion. It is particularly designed to give the editor's interpretation and opinion on reported or published news of national interest. It is a journalistic essay whose thrust is to inform or explain, persuade or convince or stimulate insight in a pleasing manner (Ogunwale, 2008). Depending on the news medium or the editor's preference, an editorial is called different names such as editor's comment, opinion and view each of which suggests that an editorial is a product of the editor's creative explication of a reported issue to which consistent references are made.

Ashipu (2013) notes that the editor's comments on news items of especially national interest which can be political, economic, educational, religious or general sociol-cultural issues bordering on the people's welfare are called editorials. Thus, editorials are meant to shed light on 'trending issues' purposely to provide enlightenment (Jegede, 2019: 22). Their scope is therefore wide and this poses a challenge to the editor's stylistic ingenuity. As an evaluative writing, an editorial appeals to both the reader's mind and feeling and apt stylistic devices serve as its effective means of appraisal (http//studfiles.net).

The ideology of a newspaper can be easily gleaned from its editorials as they represent the paper's official opinions on issues analyzed (Afolabi, 2012; Duyile, 2005 and Medubi, 2007). This is perhaps why the editorial department of a newspaper company constitutes its intellectual powerhouse by comprising the elite corps of the media establishment (Ganiyu, 2004). The text of an editorial is therefore expected to be rich in its artistic composition and worthwhile in its content. This partly justifies the continuous interest of linguists in the study of editorials.

Alizera (2011) studies modality in newspaper editorials selected from an American newspaper - The New York Times, and a Persian English Daily -Tehran Times. The study reveals that modal auxiliaries, modal adverbs, evaluative adjectives, reporting verbs and generic phrases are the means employed to express modality in the editorials. It establishes the argument that editorials are not mere reports but judgments of the editors on the news reported. Though purely linguistic in its approach, the work is limited to the study of modality.

Ashipu (2013) examines the rhetorical devices in editorials selected from two popular Nigerian magazines - News watch and Tell. The paper studies the persuasive and emotional effects of the language use in editorial. Its thrust is the editors' deployment of tropes in their editorial compositions. It finds that simile; metaphor, hyperbole, personification and rhetorical question among others are carefully employed to achieve graphical presentation and consequently emotional arousal. It concludes that rhetorical devices serve to embellish the editors' thoughts. The rhetorical analysis is rather literary with its focus mainly on figures of speech.

Sajo (2014) similarly studies one editorial from each of two Nigerian newspapers. The first is from The Sun newspaper edition of $9^{\text {th }}$ November, 2012 while the other is from the weekly edition of Leadership Hausa newspaper of $3^{\text {rd }}$ October to $6^{\text {th }}$ November 2012. The study attempts to establish the place of cohesive resources in media discourse effectiveness. It finds the preponderance of lexical and referential cohesive devices in the editorials and concludes that their apt use projects the editors' level of competence.

The editorial is a comment or a report on report and therefore a special text type targeted at achieving conviction. The studies reviewed focus on modality, rhetoric and cohesion and each is invariably a comparative study. The current study is perhaps a broader linguistic study and a fairly thorough analysis of general editorial style. Thus, its data is the Daily Trust editorial of September, 3, 2015 . 


\section{The Concern of Stylistics}

Stylistics is a branch of linguistics that emerges from the expansion in the scope of language study. Like pragmatics, discourse analysis, sociolinguistics and other areas of linguistic study whose motivation is the explanation of the functional use of language, stylistics is an interpretative study that thrives on the employment of linguistic constructs or models in the study of especially real texts. It is the study of the style conscious or otherwise that results in the composition of a text. The analysis of style involves a systematic examination of the formal features of a text and explanation of their functional essence in textual interpretation (Wales, 1989).

Stylistics began with the study of the language of literary text considered to be a deviation from the language of daily conversation but its focus from the current practice covers all forms of texts - written or spoken. Distinction is therefore drawn between literary and non-literary stylistics. Referring to the former, Fabb (1977) describes stylistics as the use of linguistics in the analysis of a particular literary text to reveal function and communicative value. Finch (2000), on the other hand, captures the focus of the latter as the use of methodology of linguistics to study the concept of style in language. The non-literary stylistics is also described as linguistic stylistics. The interface between the two forms is the application of linguistic principles in the explication of texts. Thus, stylistic analysis is an exercise intended to 'find the artistic principles underlying the writer's choice of language' (Leech and Short, 1987:74) with the aim of prescribing or proffering an objective reading of the text. Reference is made in the analysis that follows to each paragraph (p) in the eightparagraph editorial as considered necessary for ease of comprehension.

\section{Stylistic Analysis of the Editorial: MDAs and Military Debt to Discos}

The Daily Trust editorial of Thursday September 3, 2015 titled 'MDAs and Military Debt to Discos' presents the painful complaints by the Director, Research and Advocacy of the Association of Nigerian Electricity Distribution (ANED), Mr. Sunday Oduntan on the huge unpaid debt by military formation in Nigeria and Government ministries, departments and agencies (MDAs). The plight of the ANED which seems abnormal attracts the editor's attention.

First, the issue is presented objectively through adequate references to its source as well as time and place of its report. Reporting verbs are used in good number to foreground and disclose the sources of the information on which the editor's opinion is based. These include:

'Electricity distribution companies have threatened to...' (p.1)
'Speaking with the journalist in Abeokuta...' (p.2)
'Mr. Sunday Oduntan said that....'
'A breakdown of electricity debts given by....'(p.3)

The various verbs - 'threatened', 'speaking', 'said,' and 'given', are employed to distance the editor from the report and relate it appropriately to ANED and particularly to her representative, Mr. Oduntan. The verbs especially the second and third also reveal the medium employed by the source as oral. The adverbial phrase 'in Abeokuta' functions to locate the place of the interaction.

Also, the two known techniques of reporting are employed by the editor to ensure objectivity. While the first three paragraphs include indirect report (reported speech style), the next two present verbatim report given by Mr. Oduntan through the device of direct report made graphologically obvious by quotation marks:

'Of all the money we are collecting from distributing electricity to the public...' (p.4) 'In the case of nonpayment, the greatest problem we have today is the military...' (p.5) 
The quotation marks unless maliciously used are clear evidence of direct speech aimed at giving the report credibility. The first person personal pronoun 'we' in the quotations are equally complementary. Both are, therefore, apt in showing objective journalism.

In the sixth paragraph, the editor includes an additional piece of complaint lodged by his source in a way that is clearly transparent:

'He also accused military men of beating up electricity workers whenever they want to collect electricity debts...' (p.6)

The editor's preference for the reporting verb 'accused' shows his lack of prejudice and paves way for a rebuttal by the indicted military men.

Following the initial presentation of the report, the editor vigorously embarks on a critical analysis of the situation through lexical and structural predilections. First, the huge debt owed by the government agencies is described as 'unfortunate' (p.6) and 'embarrassing (p.7). The two adjectives are pejorative. The first is morphologically transparent with its initiation by the negative prefix 'un-' while the second is semantically non complimentary. The two are apt in projecting the government agencies' act of discomforting the nation as awkward and generally condemnable. The editor's condemnation of the agencies' and government's stance is predicated upon the primacy of effective power supply in national development and shared morality demand.

The two words are therefore chosen to show a reversal of the citizenry's normal expectation. The government agencies are expected to exemplify compliance but they are the culprits. This contrast justifies the editor's choice. The analysis is advanced through heavy interrogative sentences with the first two presented in paragraph six:

\section{'If government agencies cannot pay their bills, what moral right will they have to insist that private companies and individuals pay debts? The amount being owed is enough to cripple the distribution company, so how can the same government claim that it is interested in improving power supply if it cannot compel its agencies to pay for what is consumed?' (p.6)}

The two questions are rhetorical as they require more of silent testimony than oral response by the reader of the editorial. Intense conviction is the motive behind the use of rhetorical question and it is also intended to provoke thought (Ashipu, 2013). The questions are philosophical and fundamental to the argument of the editor. Structurally, the questions are peculiar. The typical theme of an interrogative sentence is unmarked. Contrariwise, the unmarked themes in the two sentences are underplayed by their overt or covert initial conditional clauses constituting marked themes. This markedness foregrounds the premise against which each of the questions is to be understood as a powerful assertion rather than a demanding question. The overridden themes - 'why' and how' - are merely assertive or prognostic rather than interrogative. The initial clause in the second sentence is arguably an adverbial clause of condition like the one in the first clause of the first sentence. It can be initiated with 'if' and the two sentences are parallel in this regard. The editor is invariably arguing that the government has no moral right to insist that private companies and individual users pay for the electricity they consume since she has been defaulting in boosting power supply. The stylistic felicity achieved through parallelism and calculated dislocation justifies Agu's (2015) position that journalism is practiced by professionals in the art of information dissemination.

In an attempt to ensure balanced criticism, the editor acknowledges the fact that Nigerian power consumers are generally culpable through a generic statement: 'it is true that often times people do not want to pay bills because of the epileptic nature of supply' (p.7) but debunks the alibi in the next three clauses in the same sentence through the same device of rhetorical interrogative that:

'...but how can the sector improve if payment is not made for what is supplied, however little?' (p.7) 
Through this question, the people's common argument is flawed and implication of their action tactically spelt out. The question is followed by another one in the editorial that is suggestive of misappropriation or corruption by the military. The editor asks:

\section{In the past few years, security agencies have been receiving huge sums in budgetary allocations; why then is the military the biggest debtor? (p.7)}

The question of the rationale behind the military's debt in spite of her huge budgetary allocation and security vote is at least suggestive of mismanagement. The editor is particularly disgusted about the status of the military as the leading defaulter, and finds this unacceptable. The question challenges the financial discipline capacity and or probity of the military and asks for explanation. Although similar in structure with the displacement of its wh- word or theme it is typically a demanding interrogative.

The last of the five questions that form the stylistic tool for the editor's probe boarders on the military's act of beating up electricity marketers for demanding payment for their power consumption. Once again the editor predicates his argument on morality as he asks:

\section{'If this trend continues, what moral right would it have to step in and maintain law and order if the matter is between civilians and power distribution companies' (p.8)}

This question which concludes the editorial underlies the fact that the military action is contradictory to its law enforcement duty and can weaken its psychological basis. It is structurally parallel to the initial three in its introduction by the if-clause. It is equally rhetorical and as such it is a 'forceful statement' (Quirk and Greenbaum, 1973; 206). The parallel questions are premeditated and calculated at the articulation of undeniable opinion. Their function according to Chicogu and Ofuani (2014) include rhetorical emphasis, multidimensional representation, specification and particularization.

Apt lexical choices help the editor to present the report and express his precise critical opinion on it. The insincerity of the government agencies is matched by their description as 'biggest debtors' (p.7),' greatest culprits' (p.6), and their action as meant to 'cripple distribution'(p.7). By describing the agencies as 'debtors', the editor characterizes them appropriately as financial defaulters punishable by law. The superlatives 'biggest' and greatest' are evaluative and they presuppose that the agencies culpability is un parallel while the legal register 'culprits' presents the government agencies as law breakers. Similarly, their crime is made more manifest in the editor's description of its implication as capable of crippling the system. The graphic transitive verb 'cripple' underlines the destructive effect of indebtedness of the agencies on power generation and distribution and also characterizes distribution appropriately as a lively activity. The choice is the verb 'cripple' in place of other lexical substitutes such as: reduce, affect and jeopardize involves deviation. 'Cripple' is more typically a register of physical disability and anatomy which is metaphorically employed in the discussion of commerce for stylistic efficacy.

The editor following critical analysis does not disguise his disapproval of the government agencies indebtedness to the electricity company. He unambiguously states:

\section{We therefore condemn the act and urge all affected ministries and agencies to pay up the debt (p.7)}

The editor's choice of the speech act or performative verbs - 'condemn' and 'urge' attests to the consciousness and commitment to his action a stylistic strategy to convince the readers. Both the condemnation and the consequent recommendation are presented as equally sacrosanct via the additive 'and'. Other recommendations are coded as urgent and not debatable through the editor's choice of the high modals as follows:

$$
\begin{gathered}
\text { Government at all levels must be responsive... (p.) } \\
\text { The military must also understand that, ... it } \\
\text { ought to comport itself appropriately (p.8) }
\end{gathered}
$$


The choices of the positive high modal operators' must' and 'ought to' in the two recommendations enables the editor to stress the obligations of the government and or its agencies and present such duties as urgent for the purpose of achieving effective persuasion.

\section{Conclusion}

The editorial studied reveals the editor's commitment to fair but critical analysis of the odd situation reported by the spokesman of the Nigerian electricity distributors. The editor's attention is caught by the report of the huge debt owed by the government in contradistinction to the constant claim of her resolve to improve power supply. The reader is unavoidably invited to read with candor through the editor's establishment of the source of the report. The opinion expressed is made quite convincing and acceptable too in a number of ways. The reader is made to share the thought of the editor through heavily modified rhetorical interrogatives. The immorality in the military's action is projected in a way that relates to the tenets of its profession through a complex interrogative sentence. Apt lexical choices with the right nuances of meaning are used to make the editorial balanced and desirable. The modalized recommendations are equally apposite both for their politeness and tone of urgency intended to lure the government to act responsibly. These constitute the editor's bases for the rigorous analyses.

\section{References:}

[1] Afolabi. S.O., A critical Discourse Analysis of Editorials from the Punch and Nigerian Tribune newspapers, American Journal of Linguistics, 1 (2)(2012), 40-46

[2] Agu. I. E., A linguistic stylistic analysis of newspaper reportage, International Journal of Research in Humanities and Social Studies, 2(8)(2015), 20-27

[3] Alizera. B., Linguistic manifestation of modality in newspaper editorials, International Journal of Linguistics, 3 (1)(2011), 1-13, https://doi.org/10.5296/ijl.v3i1.799

[4] Asipu. K. B. C., A rhetorical analysis of selected editorials of News watch and Tell Magazines, Studies in Literature and Language. 6 (1)(2013), 48-53.

[5] Chikogu. R. N., \& Ofuani. A. O., Syntactic structure and aesthetic function in Ben Okiri's The famished road circle, JALAL, Journal of Languages and Literatures, 5 (1)(2014), 235-56.

[6] Duyile. D., Writing for the media: A manual for African journalists, Lagos: Gong Communication, 2005

[7] Fabb. N., Linguistics and literature, Oxford: Blackwell, (2007)

[8] Finch. G. P., Key concepts: Linguistic terms and concepts, Tokyo: Palgrave; Macmillan, (2000)

[9] Ganiyu. M., Reporter's companion: A complete guide to news reporting and writing, Ibadan: Emgee Books, (2004)

[10] Jegede, O. O., Participant roles in selected Nigerian newspaper editorials, Bulletin of Advanced English Studies, 2 (1)(2019), 19-26, https://doi.org//10.31559/baes2019.2.1.3

[11] Leech. G. N., \& Short. M. H., Style in fiction, Harlow: Longman, (1981)

[12] Medubi. O., The fundamentals of journalism, in Obafemi. O., Ajadi. G. A., and Alabi. V. A., (eds.) Critical perspectives on English language and literature (2007), 103-116, Ilorin: Department of English. 
[13] Ogunwale. T. A., Advanced editorial writing and specialized reporting, Ibadan: Penprience press services, (2008)

[14] Quirk. R., \& Greenbaum. S., University grammar of English. London: Longman, (1973)

[15] Sajo. M. A., Cohesive devices in Nigerian media discourse: A study of Leadership (Hausa) and The Sun newspaper.' in JALAL : Journal of Language and Literature 5 (1)(2014), 79-9.

[16] Wales, K. A., Dictionary of stylistics, London: Longman, (1984) 